\title{
Left ventricular filling pressure in male patients with type 2 diabetes and normal versus low total testosterone levels
}

\author{
Matias Tinetti ${ }^{1}$, Michael Gysel ${ }^{2}$, Javier Farias ${ }^{3}$, \\ Mariano Ferrer ${ }^{4}$, Martin Lombardero ${ }^{1}$, Adrian Baranchuk ${ }^{2}$ \\ ${ }^{1}$ Department of Cardiac Imaging, Sanatorio de la Trinidad Palermo. Buenos Aires, Argentina \\ ${ }^{2}$ Arrhythmia Service, Kingston General Hospital, Queen's University, Kingston, Ontario, Canada \\ ${ }^{3}$ Sanatorio Guemes, Buenos Aires, Argentina \\ ${ }^{4}$ Department of Cardiology Instituto Medico Central, Buenos Aires, Argentina
}

\begin{abstract}
Background: Heart failure is a common complication of diabetes characterized by an elevation in left ventricular filling pressures (LVF) that often develops in the absence of clinical symptoms. Diastolic dysfunction in the setting of low total testosterone (LTT) occurs through changes in the regulation of peripheral hemodynamics. LTT is highly prevalent among individuals with type 2 diabetes. The aim of this study was to compare LVF in male diabetic patients with no structural heart disease and normal serum testosterone levels vs. those with LTT. Methods: Type 2 diabetic patients were assessed using tissue Doppler imaging to evaluate LVF and other conventional parameters of diastolic function. The E/e' ratio was used to estimate LVF through the ratio of peak passive trans-mitral left ventricular inflow velocity to the peak passive inflow velocity at the lateral mitral annulus. Patients were assigned to one of two groups based upon their total testosterone levels. Group A consisted of low $(<3.5 \mathrm{ng} / \mathrm{mL})$ testosterone levels and group B consisted of normal (> $3.5 \mathrm{ng} / \mathrm{mL})$ testosterone levels.
\end{abstract}

Results: A total of 148 male patients were included: group $A-47$ (32\%) patients; group $B-$ $101(68 \%)$ patients, respectively. Mean age was $58 \pm 5.8$ years and mean time of diabetes evolution was $7 \pm 3.1$ years. There were no significant differences between the groups regarding age, duration of diabetes evolution, hypertension, weight, heart rate, body mass index, and echocardiographic parameters. The E/e' ratio for group $A$ was $8.05 \pm 1.9$ vs. $6.1 \pm 1.7$ for group $B$ $(p<0.0001)$. The $E / A$ ratio was $0.94 \pm 0.10$ vs. $1.19 \pm 0.12(p=0.01)$, deceleration time $242 \pm 7.4 \mathrm{~ms} v$ s. $205 \pm 9 \mathrm{~ms}(p=0.026)$ and systolic pulmonary artery pressure $27 \pm$ $\pm 2.2 \mathrm{~mm} \mathrm{Hg} v$ s. $22 \pm 1.7 \mathrm{~mm} \mathrm{Hg}(p=0.11)$.

Conclusions: Patients with type 2 diabetes and LTT have a higher E/e' ratio demonstrating a pre-clinical increase in LVF when compared to similar patients with normal testosterone levels. This finding is independent of time of diabetes evolution, hypertension and other echocardiographic parameters. (Cardiol J 2015; 22, 2: 206-211)

Key words: diabetes, left ventricular filling pressures, total testosterone, heart failure

Address for correspondence: Matias Tinetti, MD, Department of Cardiac Imaging, Sanatorio de la Trinidad Palermo. Buenos Aires, Argentina, tel: +54 11 32729796, fax: +54 11 39678762, e-mail: matiastinetti@hotmail.com 


\section{Introduction}

Hypogonadotropic hypogonadism is characterized by low plasma concentrations of testosterone as well as inappropriately low levels of luteinizing hormone (LH) and follicle stimulating hormone (FSH). The prevalence of hypogonadotropic hypogonadism in male patients with type 2 diabetes is high, affecting nearly $30 \%$ of individuals. In contrast, this condition is relatively uncommon in type 1 diabetes $[1,2]$. Heart failure (HF) is another frequent complication of diabetes that occurs through a variety of mechanisms. Current evidence indicates that myocardial damage in diabetic patients affects diastolic function before systolic function [3]. Patients who develop HF in the setting of diastolic dysfunction have increased left ventricular filling pressures (LVF) that can occur years before symptom onset and even in the absence of apparent structural heart disease.

In recent years, a large body of literature has emerged suggesting a link between androgen deficiency and cardiovascular disease [4-6]. Testosterone deficiency has been shown to be an independent risk factor for poor outcomes in $\mathrm{HF}$ patients. Furthermore, it has also been identified as an independent marker of reduced exercise capacity in HF $[7,8]$. Testosterone is thought to influence diastolic function through its impact on peripheral hemodynamics [9].

Pulsed tissue Doppler imaging (TDI) has been validated as a reliable index of LVF, using the $\mathrm{E} / \mathrm{e}^{\prime}$ ratio [10]. In this parameter, the ratio of early peak trans-mitral inflow velocity (E) to early peak velocity at the lateral mitral annulus (e') is calculated. The E/e' ratio is used to detect and follow the progression of diastolic dysfunction in asymptomatic diabetic patients [11]. In spite of this, the influence of testosterone on LVF in these patients remains uncertain.

The aim of this study was to compare LVF in male diabetic patients with no structural heart disease and normal testosterone levels to those with low total testosterone (LTT).

\section{Methods}

\section{Patient population}

In total, 148 male patients in the age of 20 and 65 years old ( $58 \pm 5.8$ years) with type 2 diabetes were included. Type 2 diabetes was diagnosed in accordance with The Expert Committee on the Diagnosis and Classification of Diabetes Mellitus [12]. Patients were excluded if they had been castrated as treatment for testicular or prostate cancer or if they were taking any medications known to affect sex hormone concentrations. Patients had no prior history of cardiovascular disease (myocardial infarction, ischemic stroke), HF, cardiovascular symptoms (dyspnea, orthopnea, paroxysmal nocturnal dyspnea, and angina pectoris) or asymptomatic cardiomyopathy. Arrhythmias (atrial fibrillation, frequent ectopic ventricular or supraventricular beats) or diastolic dysfunction $\left(E / e^{\prime}>15\right)$ resulted in exclusion from the study. Echocardiographic abnormalities such as left ventricular hypertrophy or valvular heart disease also resulted in exclusion from the study. Questionnaires were given to determine the duration of diabetes evolution as well as medical treatment undertaken for diabetes, hypertension and dyslipidemia. Body mass index (BMI), blood pressure and heart rate were measured at the time of echocardiography.

\section{Study design}

Prospective observational study of consecutive patients with type 2 diabetes recruited between September 2010 and November 2012.

Patients were assigned to one of two groups depending upon total serum testosterone levels. Patients with total serum testosterone levels below $3.5 \mathrm{ng} / \mathrm{mL}$ were assigned to group A while patients with levels greater that $3.5 \mathrm{ng} / \mathrm{mL}$ were assigned to group B, based on a previously published consensus statement from the International Society of Andrology, European Association of Andrology and the American Society of Andrology that defined the cut-off value to consider hypogonadism [13].

Testosterone assessment was always conducted between $7 \mathrm{AM}$ and $10 \mathrm{AM}$. Venous blood samples were taken: serum samples were obtained by centrifugation and immediately frozen for further analysis. Total testosterone level was measured by quimioluminiscence (ng-mL). In all patients, FSH, LH and prolactin was measured in order to rule out hypothalamic pituitary gonadal axis disease. Patients provided written consents to participate in the study.

\section{Echocardiography}

Imaging was performed using General Electric Vivid $7^{\circledast}$ (GE Health care, Chalfont St. Giles, United Kingdom) operated by an expert ultrasonographer who was blinded to patient testosterone levels. Chamber dimensions were evaluated using standard procedures, including left ventricle (LV) mass index [14] and left atrial (LA) volume index [15]. Mitral and pulmonary venous Doppler flow veloci- 
ties were recorded in the apical 4-chamber view as previously described [16]. Mitral inflow measurements included peak early (E) and peak late (A) flow velocities, the $\mathrm{E} / \mathrm{A}$ ratio, the deceleration time (DT) of early mitral flow velocity, and the isovolumic relaxation time (IVRT). Assessment of LVF was performed using TDI to calculate the $\mathrm{E} / \mathrm{e}$ ' ratio. The parameter was obtained by measuring the peak trans-mitral LV inflow velocity (E) and the peak velocity at the lateral mitral annulus during passive filling (e'). The ratio was calculated as an average of 3 consecutive measurements; and both groups were compared. Adequate mitral and TDI signals were recorded in all patients, whereas pulmonary venous flow signals were suitable for analysis in only $55 \%$ of the cases. That was the reason because we did not include pulmonary venous flow results in the final analysis.

\section{Statistical analysis}

Data were analyzed using Stata 12 software (College Station, Texas USA). Descriptive statistics are presented as mean \pm standard deviation for continuous data and relative frequencies for categorical variables. Data were analyzed using the Mann-Whitney U test and $\chi^{2}$. Relationships between the serum testosterone concentration and $\mathrm{E} / \mathrm{e}$ ' ratio, age, glycemic control, and other variables were examined by linear regression analysis. Multiple regression analysis was performed to assess the combined influence of variables on the mean $\mathrm{E} / \mathrm{e}$ ' ratio. To examine the effects of various factors on mean E/e' ratio the following factors were considered independent variables: BMI, systolic blood pressure, total cholesterol and glycated hemoglobin (HbA1c). Statistical significance was defined as a $\mathrm{p}$ value $<0.05$.

\section{Results}

The clinical characteristics of the population are described in Table 1 . Mean age was $58 \pm 5.8$ years; duration of diabetes evolution was $7 \pm$ \pm 3.1 years. $\mathrm{HbA} 1 \mathrm{c}$ was $6.9 \pm 0.6 \%$, and $\mathrm{BMI}$ was $30.1 \pm 3 \mathrm{~kg} / \mathrm{m}^{2}$. The prevalence of hypertension was $65 \%$. There were no significant differences between the LTT and normal testosterone groups. The mean value of total testosterone was $2.9 \pm$ $\pm 0.54 \mathrm{ng} / \mathrm{mL}$ in group A and $5.1 \pm 1.31 \mathrm{ng} / \mathrm{mL}$ in group B ( $<0.001)$ (Table 2). Medical therapy for diabetes, hypertension and dyslipidemia did not differ significantly between the groups (Fig. 1).

The E/e' ratio for group A was $8.05 \pm 1.9$ vs. $6.1 \pm 1.7$ for group B; $p<0.0001$ (Fig. 2). Other
Table 1. Characteristics of the population $(n=148)$.

\begin{tabular}{lc}
\hline Age [years] & $58 \pm 5.8$ \\
Duration of diabetes [years] & $7 \pm 3.1$ \\
Glycated hemoglobin $\left(\mathrm{HbA}_{1 \mathrm{cc}}\right)[\%]$ & $6.9 \pm 0.6$ \\
Body mass index $\left[\mathrm{kg} / \mathrm{m}^{2}\right]$ & $30.1 \pm 3$ \\
Total testosterone $[\mathrm{ng} / \mathrm{mL}]$ & $4.66 \pm 1.65$ \\
Hypertension & $65.5 \%$ \\
Low density lipoprotein $[\mathrm{mg} / \mathrm{dL}]$ & $119.3 \pm 23$ \\
High density lipoprotein $[\mathrm{mg} / \mathrm{dL}]$ & $39.9 \pm 7$ \\
Glucose fasting $[\mathrm{mg} / \mathrm{dL}]$ & $133 \pm 28.9$ \\
Heart rate $[\mathrm{bpm}]$ & $68 \pm 5.8$ \\
Left atrial volume $\left[\mathrm{mm}{ }^{3}\right]$ & $50.1 \pm 14$ \\
Septal thickness $[\mathrm{mm}]$ & $9.5 \pm 1.3$ \\
Ejection fraction $[\%]$ & $61 \pm 2.2$ \\
Left ventricular mass index $\left[\mathrm{g} / \mathrm{m}^{2}\right]$ & $80 \pm 11$ \\
Left atrial volume index $\left[\mathrm{mL} / \mathrm{m}^{2}\right]$ & $17.9 \pm 1.3$ \\
\hline
\end{tabular}

parameters of $\mathrm{LV}$ filling as $\mathrm{E} / \mathrm{A}$ ratio $(0.94 \pm 0.10$ vs. $1.19 \pm 0.12, \mathrm{p}=0.01)$, and DT $(242 \pm 7.4 \mathrm{~ms}$ vs. $205 \pm 9 \mathrm{~ms}(\mathrm{p}=0.026)$ showed significant differences between groups. The systolic pulmonary artery pressures did not differ between groups. Group A had a 6-fold increased risk of an E/e' ratio $>5$ (group $\mathrm{A}=91.67 \%$ vs. group $\mathrm{B}=64.56 \%$; odds ratio $=6.04$; confidence interval $=1.69-21.47$; $\mathrm{p}=0.005)$. Differences remained significant after adjustment for age, duration of diabetes evolution, BMI, lipids, HbA1c and drug treatment. Multiple regression analyses did not demonstrate any relationship between $\mathrm{E} / \mathrm{e}^{\prime}$ and medical treatment, the presence of hypertension, or other cardiovascular risk factors.

\section{Discussion}

The prevalence of type 2 diabetes has increased dramatically over the past two decades. This has been mirrored by a corresponding increase in the rates of obesity and sedentary life style [17]. Cardiovascular disease is the primary cause of morbidity and mortality in these patients, with numerous studies identifying a strong association between diabetes and the development of LV structural abnormalities. This process is independent of other relevant covariates such as BMI and increased arterial pressure [18]. Even in the presence of normal chamber anatomic characteristics, diabetes has been found to negatively affect systolic mechanics and diastolic filling [19]. Clearly, the development of $\mathrm{HF}$ in diabetic patients is common and frequently associated with a poor prognosis. 
Table 2. Baseline clinical, biochemical and echocardiographic characteristics of groups with low (group A) and normal (group B) testosterone levels.

\begin{tabular}{|c|c|c|c|}
\hline Characteristics & Group A (n = 47) & Group B $(n=101)$ & $\mathbf{P}$ \\
\hline Age [years] & $58 \pm 7.01$ & $59 \pm 5.8$ & NS \\
\hline Duration of diabetes [years] & $6 \pm 3.19$ & $7 \pm 3.06$ & 0.21 \\
\hline Weight [kg] & $88 \pm 13.77$ & $90 \pm 9.8$ & 0.45 \\
\hline Height [cm] & $174 \pm 0.06$ & $173 \pm 0.05$ & NS \\
\hline Body mass index $\left[\mathrm{kg} / \mathrm{m}^{2}\right]$ & $29.05 \pm 3.86$ & $29.84 \pm 2.86$ & NS \\
\hline Heart rate $[\mathrm{bpm}]$ & $64.5 \pm 9,65$ & $70.5 \pm 8.42$ & 0.089 \\
\hline Triglicerydes [mg/dL] & $130 \pm 74.02$ & $124 \pm 27.86$ & 0.098 \\
\hline Low density lipoprotein [mg/dL] & $118 \pm 24.46$ & $127 \pm 23.16$ & 0.17 \\
\hline High density lipoprotein [mg/dL] & $41 \pm 8.29$ & $37 \pm 6.77$ & 0.06 \\
\hline Glycated hemoglobin (HbA1c) [\%] & $6.9 \pm 1.04$ & $7.05 \pm 0.58$ & 0.41 \\
\hline Fasting glycemia [mg/dL] & $132 \pm 28.32$ & $133 \pm 14.52$ & NS \\
\hline Total testosterone $[\mathrm{ng} / \mathrm{mL}]$ & $2.9 \pm 0.54$ & $5.1 \pm 1.31$ & 0.001 \\
\hline $\mathrm{E}[\mathrm{m} / \mathrm{s}]$ & $0.80 \pm 0.16$ & $0.73 \pm 0.12$ & 0.160 \\
\hline$A[\mathrm{~m} / \mathrm{s}]$ & $0.85 \pm 0.14$ & $0.61 \pm 0.13$ & 0.001 \\
\hline$E / A$ & $0.94 \pm 0.10$ & $1.19 \pm 0.12$ & 0.01 \\
\hline Deceleration time $[\mathrm{m} / \mathrm{s}]$ & $242 \pm 7.4$ & $205 \pm 9$ & 0.026 \\
\hline $\mathrm{E} / \mathrm{e}^{\prime}$ ratio & $8.05 \pm 1.9$ & $6.1 \pm 1.78$ & 0.001 \\
\hline Systolic pulmonary artery pressure $[\mathrm{mm} \mathrm{Hg}]$ & $27 \pm 2.2$ & $22 \pm 1.7$ & 0.11 \\
\hline Left ventricular ejection fraction [\%] & $61.5 \pm 3.24$ & $60.5 \pm 4.24$ & NS \\
\hline Left ventricular diastolic diameter [mm] & $47 \pm 1.5$ & $46 \pm 4.20$ & NS \\
\hline Septal thickness [mm] & $9.5 \pm 2.3$ & $9.4 \pm 2.1$ & NS \\
\hline Left atrial volume index $\left[\mathrm{mL} / \mathrm{m}^{2}\right]$ & $18.3 \pm 1.9$ & $17.7 \pm 1.5$ & NS \\
\hline Left ventricular mass index $\left[\mathrm{g} / \mathrm{m}^{2}\right]$ & $81 \pm 9$ & $79 \pm 13$ & NS \\
\hline
\end{tabular}

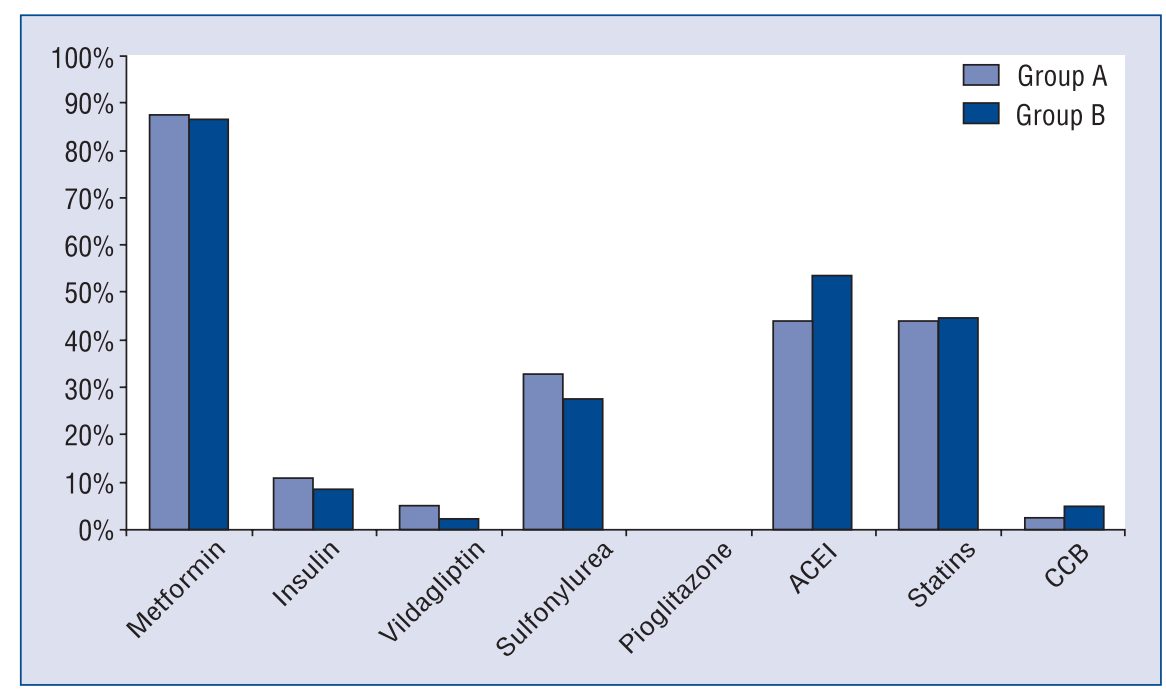

Figure 1. Medical treatment; ACEI — angiotensin converting enzyme inhibitors; CCB - calcium channel blockers.

In a prospective study by From et al. [20], it was found that for every 1.0 increment in the $\mathrm{E} / \mathrm{e}$ ' ratio, the hazard ratio of developing $\mathrm{HF}$ increased by $3 \%$ in asymptomatic diabetic patients. This study highlights the importance of LVF as a prognostic risk factor for the development of HF even in the absence of clinical symptoms. In addition to this, diabetics have a significantly higher prevalence of 


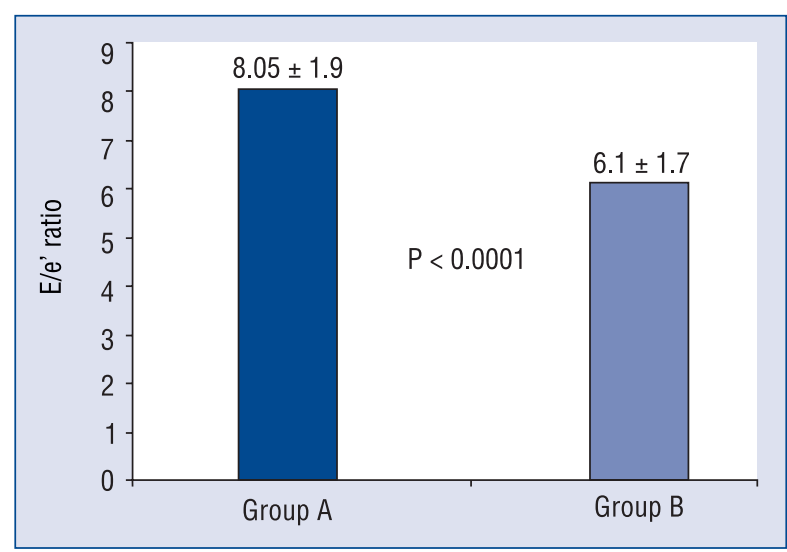

Figure 2. Differences between groups in $\mathrm{E} / \mathrm{e}^{\prime}$ ratio.

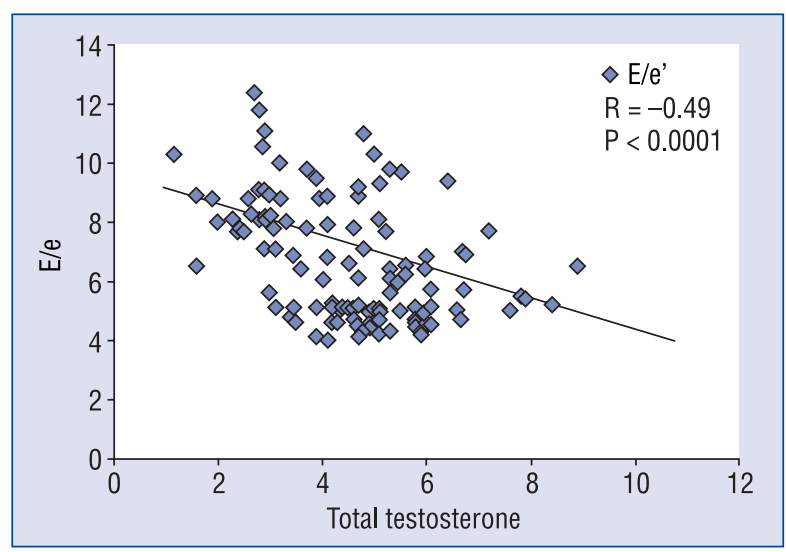

Figure 3. Correlation between total testosterone and $\mathrm{E} / \mathrm{e}^{\prime}$ ratio.

hypogonadism than individuals without diabetes [21]. The high incidence of LTT in male patients with type 2 diabetes is thought to be the result of a complex interaction between multiple endocrine processes. High rates of peripheral conversion of testosterone to estrogen occur through increased aromatase activity in the setting of hyperinsulinemia and elevated inflammatory cytokines. This process is further exacerbated by visceral obesity. Hyperinsulinemia and increased cytokine levels also lead to a decreased release of gonadotropin releasing hormone $(\mathrm{GnRH})$ and $\mathrm{LH}$ by the central nervous system. This ultimately results in the inhibition of Leydig cell's function and decreased testosterone production [22].

Testosterone has been found to influence cardiovascular physiology through a variety of mechanisms. Current evidence indicate that testosterone may have both direct genomic and non-genomic effects on the vascular wall [23]. Additionally, it has been shown to act as a peripheral vasodilator by affecting intracellular calcium regulation and has the potential to increase cardiac output [24]. Some studies have demonstrated that androgen action is mediated by direct calcium antagonism in the vascular smooth muscle [25]. Testosterone is a powerful antagonist of L-type voltage-operated $\mathrm{Ca}^{2+}$ channels (LVOCCs). This blockade of LVOCCs induces vasorelaxation of both vascular and nonvascular smooth muscle; ultimately resulting in vasodilation of small arteries, independent of the type of endothelium [26, 27]. These findings highlight the direct role of testosterone levels on peripheral hemodynamics.

Our findings suggest that male patients with type 2 diabetes and LTT have higher LVF than those with normal testosterone levels and worst parameters of diastolic function like $\mathrm{E} / \mathrm{A}$ ratio and DT. This holds true in patients with a long diabetes evolution, good metabolic control (HbA1c), and the absence of myocardial disease or symptoms (Fig. 3). TDI indices were used as they correlate well with intra-cardiac ventricular pressure tracings in diabetic patients. We did not find significant differences between groups regarding LA volume index and pulmonary pressures (markers of advanced diastolic dysfunction disease) probably by analyzing a population without manifestations of structural heart disease.

To the best of our knowledge, there are no other studies that evaluated the influence of testosterone on LVF. Our study identified no relationship between the $\mathrm{E} / \mathrm{e}^{\prime}$ ratio and the presence of hypertension, medical therapy for diabetes, or different drug therapies that can influence vascular resistance and diastolic function. The influence of testosterone on peripheral hemodynamics should be investigated in a larger cohort of patients.

Despite advances in evidence-based pharmacological therapies, HF patients continue to exhibit significant morbidity and mortality with rates of up to $30 \%$ at 1 year [28]. Various studies suggest an important role for pre-clinical interventions and close follow-up of patients at risk for the development of HF [29]. In this study, long-term follow-up of patients with type 2 diabetes and LTT will be necessary to determine whether or not LTT will ultimately influence the development of clinical diastolic dysfunction and clinical HF. The results of the present study confirm the hypothesis that LTT could be an early marker for the development of diastolic dysfunction in male patients with diabetes. 


\section{Limitations of the study}

We carefully excluded all patients with history of coronary disease and angina or equivalent symptoms and those with positive stress test for ischemia in the last year. However, we did not perform stress test in all patients before being included in the study. Future research should also consider how silent ischemia could influence the results.

\section{Conclusions}

Male patients with type 2 diabetes and low testosterone levels have higher LV filling pressure than controls with normal testosterone levels. This finding may help detect patients at higher risk of HF development.

\section{Conflict of interest: None declared}

\section{References}

1. Dhindsa S, Prabhakar S, Sethi M et al. Frequent occurrence of hypogonadotropic hypogonadism in type 2 diabetes. J Clin Endocrinol Metab, 2004; 89: 5462-5468.

2. Tomar R, Dhindsa S, Chaudhuri A et al. Contrasting testosterone concentrations in type 1 and type 2 diabetes. Diabetes Care, 2006; 29: 1120-1122.

3. Poirier P, Bogaty P, Garneau C et al. Diastolic dysfunction in normotensive men with well-controlled type 2 diabetes: Importance of maneuvers in echocardiographic screening for preclinical diabetic cardiomyopathy. Diabetes Care, 2001; 24: 5-10.

4. Liu PY, Death AK, Handelsman DJ. Androgens and cardiovascular disease. Endo Rev, 2003; 24: 313-340.

5. Basaria S, Dobs AS. Testosterone making an entry into the cardiometabolic world. Circulation, 2007; 116: 2658-2661.

6. Montagnana M, Lippi G. Relationship between serum testosterone and cardiovascular risk profile in the general population. Arch Intern Med, 2008; 23: 1350-1351.

7. Jankowska EA, Biel B, Majda J et al. Anabolic deficiency in men with chronic heart failure: Prevalence and detrimental impact on survival. Circulation, 2006; 114: 1829-1837.

8. Jankowska EA, Biel B, Ponikowska B et al. Reduction in serum testosterone deteriorates exercise capacity in men in the course of chronic heart failure. Eur J Heart Failure, 2007; 6: 148-148.

9. Jones RD, Hugh Jones T, Channer KS. The influence of testosterone upon vascular reactivity. Eur J Endocrinol, 2004; 151: 29-37.

10. Ommen SR, Nishimura RA, Appleton CP et al. Clinical utility of Doppler echocardiography and tissue Doppler imaging in the estimation of left ventricular filling pressures: A comparative simultaneous Doppler-catheterization study. Circulation, 2000; 102: $1788-1794$.

11. Di Bonito P, Moio N, Cavuto L et al. Early detection of diabetic cardiomyopathy: Usefulness of tissue Doppler imaging. Diabet Med, 2005; 22: 1720-1725.

12. The Expert Committee on the Diagnosis and Classification of Diabetes Mellitus: Report of the expert committee on the diag- nosis and classification of diabetes mellitus. Diabetes Care, 2002; 25: S5-S20.

13. Wang $\mathrm{C}$, Nieschlag $\mathrm{E}$, Swerdloff $\mathrm{R}$ et al. Investigation, treatment and monitoring of late-onset hypogonadism in males: ISA, ISSAM, EAU and ASA recommendations. J Androl, 2009; 30: 1 .

14. Devereux RB, Reichek N. Echocardiographic determination of left ventricular mass in man: Anatomic validation of the method. Circulation, 1977; 55: 613-618.

15. Murray JA, Kennedy JW, Figley MM. Quantitative angiocardiography, II: the normal left atrial volume in man. Circulation, 1968; 37: 800-804.

16. Nishimura RA, Tajik AJ. Evaluation of diastolic filling of left ventricle in health and disease: Doppler echocardiography is the clinician's Rosetta Stone. J Am Coll Cardiol, 1997; 30: 8-18.

17. Parikh NI, Pencine MJ, Wang TJ et al. Increasing trends in incidence of overweight and obesity over 5 decades. Am J Med, 2007; 120: 242-250.

18. Devereux RB, Roman MJ, Paranicas M et al. Impact of diabetes on cardiac structure and function: The Strong Heart Study. Circulation, 2000; 101: 2271-2276.

19. Palmieri V, Bella JN, Arnett DK et al. Effect of type 2 diabetes mellitus on left ventricular geometry and systolic function in hypertensive subjects. Hypertension Genetic Epidemioloy Network (Hyper-GEN) study. Circulation, 2001; 103: 102-107.

20. From A, Scott CG, Chen HH. The development of heart failure in patients with diabetes mellitus and pre-clinical diastolic dysfunction. J Am Coll Cardiol, 2010; 55: 300-3005.

21. Corona G, Mannucci E, Petrone L et al. Association of hypogonadism and type II diabetes in men attending an outpatient erectile dysfunction clinic. Int J Impot Res, 2006; 18: 190-197.

22. Wang $\mathrm{C}$, Jackson $\mathrm{G}$, Hugh Jones $\mathrm{T}$ et al. Low testosterone associated with obesity and metabolic syndrome contributed to sexual dysfunction and cardiovascular disease risk in men with type 2 diabetes. Diabetes Care, 2011; 34: 1669-1674.

23. Liu D, Dillon JS. Dehydroepiandrosterone stimulates nitric oxide release in vascular endothelial cells: Evidence for a cell surface receptor. Steroids, 2004; 69: 279-289.

24. Pugh PJ, Jones TH, Channer KS. Acute haemodynamic effects of testosterone administration in men with heart failure. Eur Heart J, 2002; 23: 28.

25. Jones RD, English KM, Jones TH et al. Testosterone-induced coronary vasodilatation occurs via a non-genomic mechanism: Evidence of a direct calcium antagonism action. Clin Sci (Lond), 2004; 107: 149-158.

26. Scragg JL, Dallas ML, Peers C. Molecular requirements for Ltype $\mathrm{Ca} 2+$ channel blockade by testosterone. Cell Calcium, 2007; 42: 11-15.

27. Navarro-Dorado J, Orensanz LM, Recio P et al. Mechanisms involved in testosterone-induced vasodilatation in pig prostatic small arteries. Life Sci, 2008; 83: 569-573.

28. Roger VL, Weston SA, Redfield MM et al. Trends in heart failure incidence and survival in a community-based population. JAMA, 2004; 292: 344-350.

29. Grady K, Dracup K, Kennedy G et al. Team management of patients with heart failure. AHA scientific statement. Circulation, 2000; 102: 2443-2456. 